\title{
La urgencia y lo indecible en las obras de Burton, Aizenberg y Fontes, tres artistas argentinos
}

L'urgence et l'indicible dans les ouvres de Burton, Aizenberg et Fontes, trois artistes argentins

Miguel Almiron

\section{Q OpenEdition}

\section{Journals}

\section{Edición electrónica}

URL: https://journals.openedition.org/agedor/6135

DOI: 10.4000/agedor.6135

ISSN: 2104-3353

\section{Editor}

Laboratoire LISAA

\section{Referencia electrónica}

Miguel Almiron, «La urgencia y lo indecible en las obras de Burton, Aizenberg y Fontes, tres artistas argentinos», L'Âge d'or [En línea], 13 | 2020, Publicado el 11 octubre 2021, consultado el 15 octubre 2021. URL: http://journals.openedition.org/agedor/6135 ; DOI: https://doi.org/10.4000/agedor.6135

Este documento fue generado automáticamente el 15 octubre 2021.

L'Âge d'or. Images dans le monde ibérique et ibéricoaméricain 


\section{La urgencia y lo indecible en las obras de Burton, Aizenberg y Fontes, tres artistas argentinos}

L'urgence et l'indicible dans les œuvres de Burton, Aizenberg et Fontes, trois artistes argentins

Miguel Almiron

\section{NOTA DEL AUTOR}

Agradezco a la Doctora Viviana Canet, especialista en Derecho Constitucional de la Universidad de Buenos Aires, por su valiosa ayuda en la elaboración del presente artículo.

“No están muertos ni vivos, están desaparecidos." J. R. Videla

\section{El escenario político: el Estado terrorista}

1 El contexto del arte en Argentina en las décadas de 1970 y 1980, fue marcado por el hecho trágico de la dictadura cívico militar que gobernó el país entre el 24 de marzo de 1976 y el 10 de diciembre de 1983, fecha en que se restablece el estado de derecho con la elección democrática de un presidente constitucional, el Dr. Raúl Alfonsín. No puede dejar de señalarse también en este escenario político la guerra de Malvinas contra el Reino Unido (1982) que hizo de una causa justa (el reclamo de soberanía sobre las islas Malvinas, Sandwich y Georgias del Sur) una cruenta pérdida de vidas fundamentalmente de jóvenes ${ }^{1}$.

2 El arte ya había dado cuenta de situaciones de violación de derechos, como son un ejemplo las acciones artísticas llevadas a cabo durante la dictadura militar que gobernó 
el país entre 1966 y 1973: Tucumán Arde (1968), Experiencias 68, II Certamen Nacional de Investigaciones Visuales (1971), Arte e ideología (1972) que serán censuradas por su contenido político de denuncia y, en algunos casos severamente intervenidas y/o prohibidas ${ }^{2}$.

Entre 1973 y 1976 se genera un breve paréntesis democrático con el gobierno peronista que en los hechos, se extiende solo hasta mediados del año 1974, tiempo en el que empieza a operar un sistema ilegal y legal ${ }^{3}$ de represión que culmina el 24 de marzo de 1976 cuando el conjunto de las fuerzas armadas derrocan al gobierno democrático e imponen la dictadura militar más sangrienta de la historia argentina.

En la década del 70, la generalización de metodologías represivas y violaciones masivas de derechos humanos se evidencia en toda Latinoamérica. El rasgo predominante es la asunción por parte del Estado de la eliminación del disenso social ejercitado bajo la forma de Estado terrorista, fundamentado en la llamada "Doctrina de la Seguridad Nacional". "El caso argentino ha sido considerado paradigmático en la aplicación de esta política, no solo por su carácter masivo sino por lo siniestro y clandestino de las metodologías utilizadas." ${ }^{4}$

5 En Argentina, en efecto, el autodenominado "Proceso de Reorganización Nacional" ejecuta un plan represivo estructurado de forma sistemática en todo el país y en el exterior sobre una red organizada en cinco zonas militares por fuera de la organización política tradicional que operó en forma clandestina en circuitos represivos y en más de 600 centros clandestinos de detención. ${ }^{5}$ Aún impera sobre esta organización un pacto de silencio revelador de la extrema racionalidad técnica aplicada a la reestructuración sociopolítica y económica de la sociedad. ${ }^{6}$ Se pone en marcha un plan de secuestro y desaparición forzada de personas en campos de cautiverio, tortura y exterminio $y$, secuestro y sustracción de identidad de niños y niñas, muchos de ellos nacidos en cautiverio. Al mismo tiempo, se operaba un cambio en el sistema socioeconómico del país como lo denuncia el periodista y escritor Rodolfo Walsh en la "Carta a la Junta Militar" (1977):

En la política económica de ese gobierno debe buscarse no sólo la explicación de sus crímenes sino una atrocidad mayor que castiga a millones de seres humanos con la miseria planificada. En un año han reducido ustedes el salario real de los trabajadores al $40 \%$, disminuido su participación en el ingreso nacional al $30 \%$, elevado de 6 a 18 horas la jornada de labor que necesita un obrero para pagar la canasta familiar, resucitando así formas de trabajo forzado que no persisten ni en los últimos reductos coloniales. Congelando salarios a culatazos... ${ }^{7}$

$6 \quad$ Si bien la represión fue grande y toda oposición censurada y desarticulada por medio del terror y del temor, se cuentan por miles los trabajadores, sindicalistas, periodistas, docentes, artistas y militantes que denunciaron y lucharon contra el terrorismo en el mismo país y en el exilio, estando muchos de ellos y ellas desaparecidos.

Las secuelas del horror y el terror van a marcar fuertemente el país y dejan en él una enorme y difícil carga a tramitar por las generaciones venideras: la primera de ellas, el peso emotivo psicosocial de un país dividido, seccionado emocionalmente, conmovido, fragilizado, y fundamentalmente herido; luego, una carga estética diversificada y conceptualizada; y finalmente, el peso que conlleva la reconstrucción social, cultural e histórica que del silencio de la violencia de lo indecible y pasando por el olvido, atravesará y reivindicará la memoria y la identidad. 


\section{Las políticas de memoria, verdad y justicia} lucha inclaudicable de las Madres y Abuelas de Plaza de Mayo que reclama con pleno respeto a los procedimientos y mecanismos democráticos por memoria, verdad y justicia.

Esta política tiene avances y retrocesos ${ }^{8}$, y es asumida plenamente recién a partir del gobierno de Néstor Kirchner en el año 2003, con pleno respaldo de los organismos de derechos humanos. Las acciones principales se centraron y aún se centran en la realización de los juicios a los represores y sus cómplices civiles en tribunales ordinarios de todo el país ${ }^{9}$, la recuperación de la identidad de las niñas y niños sustraídos y la reparación a las víctimas, si bien se fue construyendo una transversalidad de la política por la creación de áreas específicas en otros organismos de gobierno.

10 La urgencia y el tiempo no van por la misma senda. Recién en el año 2007 se inaugura el Parque Nacional de la Memoria (Monumento a las Víctimas del Terrorismo de Estado) ${ }^{10}$, es un lugar emplazado en un espacio público de 14 hectáreas, en la franja costera del Rio de la Plata, frente a las aguas donde fueran arrojados los cuerpos de miles de víctimas.

La obra se presenta como una herida en dirección del río, en donde los nombres de los detenidos-desaparecidos y asesinados entre 1969 y 1983, están asentados sobre cuatro estelas cubiertas de 30.000 placas de piedra pórfido. Algunas aun sin nombre, están a la espera de la recuperación de la identidad de las víctimas.

En este espacio de conmemoración y testimonio a las víctimas del terrorismo de Estado, las obras de arte (esculturas) interrumpen el recorrido y recuperan la ausencia, estableciendo un vínculo, un diálogo, procurando mantener viva la memoria colectiva de manera que "las generaciones actuales y futuras que lo visiten se enfrentarán allí con la memoria del horror cometido y tomarán consciencia de la necesidad de velar para que NUNCA MÁS se repitan estos hechos"11.

\section{La urgencia y lo indecible}

No es fácil sintetizar un contexto de la historia, ni seleccionar las obras de los artistas. En este ejercicio se corre un riesgo lacunario o de simplificación. Mi elección es generacional y, sobre todo, personal. Se trata de entrar en un laberinto de laberintos, en donde la representación y la transmisión de la memoria del trauma (la tragedia y la violencia), son accionadas como espejos del presente y del pasado, en donde la evocación de una época distante es necesaria para asumir el presente, completando así la escritura oficial con la escritura individual.

14 La mirada de tres artistas nos permite vislumbrar lo que nos sería vedado, un estado latente de la presencia de los ausentes que se reivindica en sus obras y nos revela así símbolos y protagonistas que accionan la memoria y la consciencia.

Tres artistas argentinos de diferentes épocas, tres testimonios que perpetúan con una mirada aguda y comprometida la transmisión y la reactualización de la memoria: Roberto Aizenberg que en 1977, plena dictadura militar, se exilia en Paris junto con su esposa Matilde Herrera, y regresa a una Argentina en democracia en 1984; Mildred

L'Âge d'or, 13 | 2020 
Burton, que vivió toda su vida en Argentina; Claudia Fontes, que durante la época de transición de la dictadura a la democracia realizaba sus estudios de arte en Buenos Aires.

\section{La imagen de lo negado}

Bajo el refinamiento y la inocencia aparente de la imagen, la artista comprometida y contestataria Mildred Burton ${ }^{12}$ (1942-2008), nacida en la provincia de Entre Ríos, esconde y simula entre sus objetos y personajes la verdadera carga emotiva de su mirada, la más profunda y sentida en su ser ${ }^{13}$.

En la década del 70, bajo el silencio forzado y el miedo cotidiano, Burton entreteje en sus obras ficción y memoria, y revierte la mirada revelando el infierno temido y presente, un territorio de muerte. En la serie Frutos del país (1975) ${ }^{14}$, insinuando literalmente los frutos de un posible paraíso, la artista nos muestra naturalezas "vivas", en donde entre las deliciosas frutas, uvas, ciruelas, duraznos, higos, granadas y otras especies autóctonas de la Argentina, se encuentran entrelazadas las fibras nerviosas de la naturaleza y las fibras nerviosas de órganos humanos. Vasos sanguíneos (venas, arterias, arteriolas y capilares) de los ojos desmembrados de un cuerpo, masas encefálicas $u$ otros órganos (manos de bebé), se abigarran con las deliciosas frutas, vaciando la sangre nutriente impulsada por el corazón. Así entre matices y formas, estas imágenes se confunden y aluden a nuevas especies provenientes de otros posibles "frutos que se extraen del país"

En su obra ${ }^{16}$ la más pulcra y refinada representación de figuras u objetos, está desplazada por detalles inquietantes que alteran la composición y declaman, vociferan, gritan la crueldad.

En La hija del torturador (1974), la figura de una niña rubia, de cejas anchas, de ojos vibrantes y labios pulposos, vestida y adornada de las más delicadas carpetillas bordadas, luce un broche en la atadura de su camisa que, confundido entre los colores de los botones, deja ver el rojo vivo de sangre que se desgrana entre su vestimenta azul. En La madre del Torturador (1980), un retrato pintado en tres cuartos de perfil, una mujer de rasgos angulares, sobria y solemne, de algunos cabellos grises, vestida de negro, adorna su cuello con un alto festón de blanco inmaculado, y luce una cadena de oro con un dije similar al cuadro de la hija del torturador.

En esta serie de retratos, más allá de la mirada de la madre que afirma con solemnidad y formalidad el orgullo de recibir un obsequio de su hijo, o que la niña de mirada vivaz, porta estremecida el obsequio de su padre, proclaman el objeto fetiche del trabajo de ese hombre. En ambos cuadros, no es una medalla de oro que está engarzada sino un pedazo de falange (de un dedo) aun desangrándose atravesado por los ganchos punzantes del broche. Ese padre, esposo e hijo, ofrece el fruto de su trabajo indigno y horripilante que es de torturar sus semejantes, víctimas de la dictadura militar. Ambas, madre-hija, representan el silencio, la complicidad, y al mismo tiempo develan un estigma del sufrimiento y lo encausan como objeto sustituto del objeto precioso para convertirlo en símbolo de lo siniestro y de la realidad circundante.

21 En estas obras lo terrible y lo siniestro son acusados desde lo bello y si por alguno tuviera la osadía de creer que la crueldad en la imagen es producto de la imaginación de la artista, en un testimonio del año 2003 Burton afirma: 
No fue mi mente corrupta la que inventó esas crueldades. No, esas obras fueron ejecutadas un verano, mientras escuchaba los detalles encontrados en los muertos N.N., desenterrados para tratar de identificarlos y poder darles sepultura definitiva en paz. ¿Qué podía pintar en Buenos Aires ese verano? Ningún artista que se precie de ello puede ser cómplice con su silencio. ${ }^{17}$

A pesar de esta lucha, durante ese periodo, muchas de sus obras estuvieron "ocultas", "enterradas en los ateliers" envejeciendo y dejando "marcas, imborrables a través del tiempo"18.

\section{La presencia de la ausencia}

Esas máculas no solo imborrables, no solo impregnadas (y a veces mismo no vistas,) atraviesan el cuerpo deshabitándolo, dejándolo vacuo. Pero al mismo tiempo, en ese desierto doloroso, como lo muestra la escultura Sin título (2003) de Roberto Aizemberg, todo vacío está lleno de la presencia de los ausentes.

Roberto Aizenberg ${ }^{19}$ (1928-1996) es uno de los artistas más importantes del arte argentino del siglo XX. Representante de la corriente surrealista y metafísica en América, su obra presenta escenas desiertas y misteriosas "en donde por momentos coexisten lo sublime y lo siniestro, una precisión perturbadora y una atmósfera mística"20.

En Padre e hijo contemplando la sombra de un día (1962), dos personajes -padre e hijotomados de la mano y de espaldas frente a un muro, observan un paisaje extraño que se dibuja y se desdibuja en estratos cambiantes por una luz que poco a poco desaparece y deja salir de las sombras extrañas manchas en la inmensidad de un mundo fantástico, misterioso y desierto. El muro opera como un mirador que separa el espacio en dos mundos. Desde esta perspectiva, una lectura de protección y enseñanza del padre al hijo parecería revelar la existencia de lo inmensurable, la presencia y la ausencia, la protección y el desamparo, lo descriptible y lo inefable.

En esta inquietante tranquilidad, como evocando el presente y al mismo tiempo el devenir insondable, la obra se revela como presagio, como una premonición de la propia vida del artista. En 1977 Aizenberg y su esposa Matilde Herrera, periodista y escritora, tras la tragedia del secuestro y desaparición forzada (entre 1976 y 1977) de los tres hijos, así como de dos nietos cuya identidad permanece aún hoy sin identificación de su compañera Herrera, se exilia en Paris y retorna a la Argentina recién en 1984.

En su obra póstuma Sin título, los personajes aluden a Martín, José y Valeria, los hijos de Matilde Herrera, dando cuenta de esta ausencia dolorosa. Se trata de una escultura compuesta de tres siluetas en bronce laminado y de grandes dimensiones $(3,90 \times 5 \mathrm{x}$ $1,70 \mathrm{~m}$ ) realizada en el 2003 a partir de bocetos del artista y lúcidamente elegida para ser emplazada frente al Río de la Plata, sitio que fue escenario de los vuelos de la muerte durante la dictadura; "estas tres formas geométricas" como lo expresan Cristina Rossi y Florencia Battiti "encierran un vacío que señala la ausencia de los cuerpos, pero al mismo tiempo, marcan su imborrable presencia". ${ }^{21}$ La obra conjuga con la misma fuerza emotiva, la acuidad de la mirada de lo imperceptible y lo palpable. 


\section{Pablo mirando el horizonte} transformado en una especie de espejo, hace que la obra refleje el rio, mostrando así la profundidad de esas aguas y revelando lo desconocido, lo acumulado, lo arrojado. Y así en un ciclo infinito, perpetúa la historia y la memoria de una época, reflejando la misma imagen de la ausencia.

\section{La vida en la urgencia y lo indecible}

En las obras de estos tres artistas, lo indecible se transforma en la urgencia de testimoniar que, si bien no se compara a la realidad inscripta, permite dejar las huellas de la memoria siempre latentes y sentir que se ha aportado desde las más simples manifestaciones, al combate contra el horror y la impunidad y, a una forma de asumir el trauma. 

reconstrucción histórica, social y política a través de la evocación de una época distante, pero como decíamos, necesaria para asumir el presente, completando así la escritura oficial, con la escritura individual, para asumir y transitar hacia el futuro. Pero en este "transitar" en este decir y hacer, es el propio cuerpo que asume, desde la propia persona, y que ha dejado y deja, todavía, el sentir latente de la ausencia.

En palabras de Matilde Herrera, militante de Abuelas de Plaza de Mayo:

Vendrán entonces ellos, los personajes, y no habrá estremecimientos. Porque ya será claro que toda cabeza puede ser objeto, que cada cuerpo brota hacia formas imprevisibles, que carne y huesos desaparecen dejando lugar al espacio. Silencio espeso, brillante, que canta, flota, se estremece. Silencio en cielos y espacios. Silencios de muerte. Silencio de vida. Silencio de otro silencio, más allá, poblado de hermosos sonidos... ${ }^{25}$

En el testimonio escrito por Mildred Burton:

Mientras concluyo este testimonio íntimo de artista que ha removido todo su ser, estoy temblando. No sé si hoy podré volver a mi tarea; la conmoción ha sido grande. Mis hijos, mis animales, mis pinceles, mis escritos, me observan inquietos. Quisiera tener el don de la síntesis para condensar mi vida y experiencias en un diskette esclarecedor, pero no es posible, mis personajes no lo permitirían. Quedarán algunas de mis obras en lugares cerrados o públicos y muchos manuscritos y ellos contarán sus historias y posiblemente la mía, la de una artista plástica latinoamericana, libre. ${ }^{26}$

\section{Y, las palabras de Claudia Fontes:}

El proceso de Reconstrucción del Retrato de Pablo Míguez fue lo más arduo y exigente que hice en mi vida desde el punto de vista emocional y ético. No sólo por la responsabilidad que implicó el trabajar con la memoria y el dolor de sus familiares, sino porque durante el proceso físico de reconstrucción de la imagen de Pablo fui madre, y el proceso de creación de la escultura y mi aprendizaje como madre estuvieron íntimamente ligados, hasta en sueños. ${ }^{27}$

\section{NOTAS}

1. Ver https://www.argentina.gob.ar/ejercito/malvinas, consultada el 4 de octubre de 2021.

2. Para más información ver Andrea Giunta, Vanguardia, internacionalismo y política. Arte argentino en los años sesenta, Buenos Aires, Paidós, 2001.

3. En 1975, en la última etapa del gobierno constitucional, se dictaron normas secretas que tenían como finalidad reglamentar la actuación de las fuerzas armadas y de seguridad en lo que se consideraba la "lucha contra la subversión", creando órganos especiales para subordinar las policías y fuerzas penitenciarias provinciales al control operacional de las fuerzas armadas, a las que se encomendó la ejecución de las operaciones dirigidas a "aniquilar el accionar de los elementos subversivos en todo el territorio del país" (Archivo Nacional de la Memoria, Cuaderno $n^{\circ} 4$ - Documentos del Estado terrorista: Directiva del Comandante General del Ejército No 404/75 (Lucha contra la subversión) y Plan del Ejército (Contribuyente al Plan de Seguridad Nacional), Buenos Aires, 2012, p. 6, disponible en http://www.jus.gob.ar/media/1129178/41-anmdocumentos_del_estado_terrorista.pdf. 
4. Secretaria de Derechos Humanos de la Nación, Consecuencias actuales del terrorismo de Estado en la salud mental, Buenos Aires, 2006, p. 9, disponible en http://www.jus.gob.ar/media/1129094/10dhpt-consecuencias_salud_mental.pdf, consultado el 5 de octubre de 2021.

5. Ver mapa en https://www.argentina.gob.ar/derechoshumanos/sitiosdememoria/ mapacentrosclandestinos $\mathrm{y}, \quad$ listado en http://www.jus.gob.ar/media/ 3122963/6._anexo_v___listado_de_ccd.pdf, consultados el 5 de octubre de 2021.

6. Entre otras publicaciones puede consultarse, Secretaria de Derechos Humanos de la Nación: Acompañamiento a testigos en los juicios contra el terrorismo de Estado. Primeras experiencias, Buenos Aires, 2009, disponible en https://biblioteca.corteidh.or.cr/documento/61762, consultada el 5 de octubre de 2021

7.

https://www.espaciomemoria.ar/descargas/

Espacio_Memoria_Carta_Abierta_a_la_Junta_Militar.pdf, p. 7, consultada el 5 de octubre de 2021.

8. En los avances se destacan el informe Nunca más (1984) producido por la Comisión Nacional sobre Desaparición de Personas (CONADEP), ver https://www.cultura.gob.ar/que-es-laconadep-9904/ consultada el 4 de octubre de 2021, y la sentencia en el juicio a las Juntas Militares en la denominada "Causa 13", que puso fin al proceso penal contra las máximas autoridades militares (10 de diciembre 1986), https://www.argentina.gob.ar/noticias/35-aniversario-de-lasentencia-del-juicio-las-juntas, consultada el 4 de octubre de 2021. A pesar de la ejemplaridad del juicio, sobreviene inmediatamente un gran retroceso por la sanción de la ley 23.492 de Punto Final (24 de diciembre de 1986) y la ley 23.521 de Obediencia Debida (1987), retroceso que culmina el 30 de diciembre de 1990 con los indultos a los ex miembros de las Juntas condenados en el histórico juicio.

9. Para ello, se diseñó un plan nacional de acompañamiento a víctimas y querellantes que culmina con la creación del Centro Ulloa y de una red de profesionales de la salud mental.

10. El proyecto fue presentado en 1997 por los organismos de derechos humanos a la Legislatura de la Ciudad de Buenos Aires, y aprobado en Ley no 46 (1998) de la Ciudad de Buenos Aires.

11. Nora Hochbaum, Parque de la Memoria - Monumento a Las Victimas del Terrorismo de Estado, Buenos Aires, Parque de la Memoria \& Gobierno de la Ciudad Autónoma de Buenos Aires, 2010, p. 25.

12. En una entrevista para un diario argentino, realizada por Alejandra Casal en el año 2002, la periodista le pregunta: “AC: ¿Cómo era el trabajo del artista durante el período de la última dictadura militar, cómo era la vinculación con el arte? MB: Trabajamos todo el tiempo que duró la Dictadura militar contra ellos, organizamos todo tipo de certámenes, a veces con temas, otras incluíamos logos, íbamos con carteles a protestar y a gritar, a manifestarnos... No teníamos gran nombre aún, comenzábamos, entonces no nos tenían muy en cuenta... sí de algún modo molestamos, y pudimos decir, reiterar las cosas y estar allí." Alejandra Casal, "Entrevista a Mildred Burton: Una Vida consagrada al arte", http://mildredburton.blogspot.com/2008/02/ mildred-burton-la-inefable_4068.html, consultada el 3 octubre de 2021.

13. Otras obras de M. Burton están disponibles en el catálogo editado por el Museo de Arte Moderno de Buenos Aires, a propósito de la exposición Fauna de un país (2020), ver https:// museomoderno.org/libros/mildred-burton-fauna-del-pais/, consultado el 5 de octubre de 2021 .

14. .La obra puede verse en el siguiente sitio internet: https://coleccion.malba.org.ar/sin-titulode-la-serie-frutos-del-pais/

15. Fabián Lebenglick, "Cerca del Abismo: Mildred Burton en la Bellas Artes", https:// www.pagina12.com.ar/1998/suple/radar/mayo/98-05-24/nota3_a.htm, consultada el 3 de octubre de 2021

16. La hija del torturador (1974), El hijo del dictador (1976), La madre del torturador (1980) y el díptico Los responsables (1972-2013), entre otras. 
17. Leonor Calvera, "Mildred Burton, testimonio de una artista plástica", https:// mujeresdelmilenio.wordpress.com/2012/12/03/mildred-burton-testimonio-de-una-artistaplastica/, consultada el 2 de octubre de 2020.

18. A. Casal, "Entrevista a Mildred Burton", op. cit.

19.

20. Victoria Verlichak, AIZENBERG. Fundación CEPPA, 2007.

21. Florencia Battiti y Cristina Rossi, "El arte de hacer memoria", in Parque de la Memoria Monumento a Las Victimas del Terrorismo de Estado, Buenos Aires, Parque de la Memoria \& Gobierno de la Ciudad Autónoma de Buenos Aires, 2010, p. 107.

22. Claudia Fontes, https://claudiafontes.com, consultada el 3 de octubre de 2021.

23. Artist Statement / Claudia Fontes, https://claudiafontes.com/artist-statement/, consultada el 3 de octubre de 2021.

24. Reconstrucción del retrato de Pablo Míguez recibió el premio del Parque de la Memoria en 1999 y, desde el 2007 está emplazada en el Rio de la Plata.

25. Citado en "El arte de hacer memoria", op. cit., p. 107.

26. Leonor Calvera, "Mildred Burton, testimonio de una artista plástica", op. cit.

27. Maria Paula Zacharias, "Claudia Fontes: Arte, historia y naturaleza”, in Hoornik, 3, 2016, p. 39.

\section{RESÚMENES}

El contexto del arte en Argentina en las décadas de 1970 y 1980, fue marcado por el hecho trágico de la dictadura cívico militar que gobernó el país entre los años 1976 y 1983, fecha en que se restablece el estado de derecho con la elección democrática de un presidente constitucional. Las secuelas del horror y el terror van a marcar fuertemente el país y dejan en él una enorme y difícil carga a tramitar por las generaciones venideras: La primera de ellas, el peso emotivo psicosocial de un país dividido, seccionado emocionalmente, conmovido, fragilizado, y fundamentalmente herido; luego, una carga estética diversificada y conceptualizada; y finalmente, el peso que conlleva la reconstrucción social, cultural e histórica que del silencio de la violencia de lo indecible y pasando por el olvido, atravesará y reivindicará la memoria y la identidad... Las turbulencias de la época darán origen a la necesidad de dejar una huella testimonial, como lo muestran las obras de Burton, Aizenberg y Fontes.

Le contexte de l'art en Argentine dans les années 1970 et 1980 a été marqué par le fait tragique de la dictature civico-militaire qui a gouverné le pays entre 1976 et 1983, avant que l'état de droit ne soit rétabli avec l'élection démocratique d'un président constitutionnel. Les séquelles de l'horreur et de la terreur vont marquer fortement le pays et laisseront une énorme charge difficile à porter aux générations futures : une charge émotive psycho-sociale d'un pays divisé, sectionné, ému, fragilisé et fondamentalement blessé; une charge esthétique largement diversifiée et conceptualisée par les mouvements artistiques antérieurs; une charge de reconstruction sociale, culturelle et historique, qui traverse le silence de la violence de l'indicible et en passant par l'oubli revendiquera de la mémoire et l'identité. Les traumatismes de l'époque font naître dans le travail artistique de Burton, Aizenberg et Fontes un besoin de laisser une empreinte testimoniale. 
ÍNDICE

Mots-clés: indicible, l'art, dictature militaire, disparition

Palabras claves: indecible, arte, desaparecidos, dictadura militar

AUTOR

MIGUEL ALMIRON

LISAA (EA 4120), Université Gustave Eiffel 